Review

\title{
Gray matter pathology in (chronic) MS: Modern views on an early observation
}

\author{
Jeroen J.G. Geurts ${ }^{\mathrm{a}, \mathrm{b}, *}$, Peter K. Stys ${ }^{c}$, A. Minagar ${ }^{\mathrm{d}}$, S. Amor ${ }^{\mathrm{a}, \mathrm{e}}$, R. Zivadinov ${ }^{\mathrm{f}}$ \\ a Dept. of Pathology, VU University Medical Center, Amsterdam, The Netherlands \\ ${ }^{\mathrm{b}}$ Dept. of Radiology, VU University Medical Center, Amsterdam, The Netherlands \\ c Dept. of Clinical Neurosciences, Hotchkiss Brain Institute, University of Calgary, AB, Canada T2N 4N1 \\ d Dept. of Neurology, Louisiana State University Health Sciences Center, Shreveport, LA 71130, USA \\ e Neuroimmunology Unit, Neuroscience Centre, Institute of Cell and Molecular Science, Barts and the London School of Medicine and Dentistry Queen Mary University of London, \\ 4 Newark Street, London E1 2AT, UK \\ ${ }^{\mathrm{f}}$ Buffalo Neuroimaging Analysis Center, Department of Neurology, State University of New York, Buffalo, NY, USA
}

\section{A R T I C L E I N F O}

Article history:

Received 9 December 2008

Received in revised form 14 January 2009

Accepted 22 January 2009

Available online 26 February 2009

Keywords:

Gray matter

Pathogenesis

MRI

Histopathology

Atrophy

Axonal

Myelin

\section{Contents}

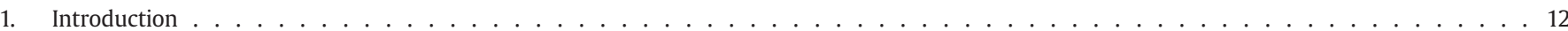

2. GM pathology in MS . . . . . . . . . . . . . . . . . . . . . . . . . . . . . . . . . . . . . . . . . . . . . 13

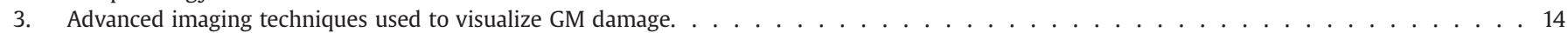

4. Pathogenic mechanisms possibly leading to GM damage . . . . . . . . . . . . . . . . . . . . . . . . . . . . . . . . . . . . . . . 15

4.1. The outside-in model. . . . . . . . . . . . . . . . . . . . . . . . . . . . . . . . . . . . . 16

4.2. The inside-out model . . . . . . . . . . . . . . . . . . . . . . . . . . . . . . . . . . . . . . . . . . . . . . . 16

5. Imaging neurodegeneration in a therapeutic setting: do we have a valid technique? . . . . . . . . . . . . . . . . . . . . . . . . . . . . 17

6. Conclusions . . . . . . . . . . . . . . . . . . . . . . . . . . . . . . . . . . . . . . . . 18

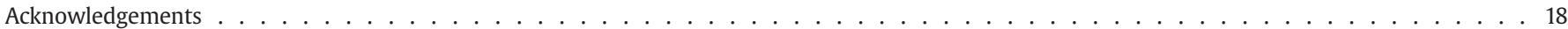

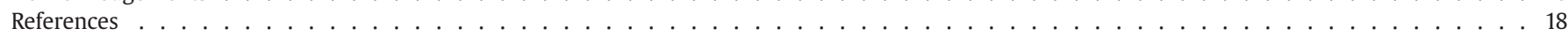

\section{Introduction}

"How is it that, one fine morning, Duchenne discovered a disease that probably existed in the time of Hippocrates? Why do we realise things so late, so poorly, with such difficulty?"

\footnotetext{
* Corresponding author. Dept. of Pathology, room 0A-090, De Boelelaan 1117, 1081 HV Amsterdam, The Netherlands. Tel.: +3120 4440341; fax: +3120 4442831.

E-mail address: j.geurts@vumc.nl (J.J.G. Geurts).
}

This question was pondered by the famous French neurologist JeanMartin Charcot (1825-1893), in remembrance of his deceased friend Guillaume-Benjamin Duchenne (de Boulogne) who had spent much time and effort on characterizing pseudohypertrophic muscular dystrophy at the end of the 19th century. Charcot's answer to his own question was: “...Because our minds have to take in something that upsets our original set of ideas." [1]

This, in a slightly different fashion, also applies to the field of multiple sclerosis (MS), where the realization that gray matter (GM) structures are heavily involved in the pathology of the disease has only really 
sunken in recently, despite early remarks from histology. In 1916, neurohistologist James W. Dawson published a comprehensive overview on the histology of disseminated sclerosis [2], and stated that: "when an area [of demyelination] is confined to the cortex, the changes are, as a rule, not nearly so marked, especially those in the deepest layers. The demyelination may reach from the surface of the convolution to varying depths, even to the border between cortex and white matter. It may lie wholly within the cortex and cut through a portion of the radiation or simply affect Baillarger's stripe. These areas are often in association with a markedly dilated vessel which penetrates from the surface almost to Baillarger's stripe, and a number of dilated changed smaller vessels lie within the area." Interestingly, noticing the striking lack of glial proliferation, the cellular paucity and the relative preservation of axons within demyelinated GM lesions, Dawson wondered: "Is then, the process that attacks the cortex different in its nature and origin from that which affects the rest of the central nervous system?" These sharp observations and this particular question, stemming from a period well before advanced immunohistochemical staining methods were introduced, have proven to be prophetic to the field.

\section{GM pathology in MS}

After the initial casuistic descriptions of demyelination in the GM of MS patients, at the beginning of the 20th century, the subject was long disregarded. This was mainly due to difficulties involved with visualizing cortical GM lesions using conventional histochemical staining procedures, as well as to a predominant attention for the more prominent process of inflammatory demyelination in the white matter (WM). In 1962, the interest in GM lesions in MS was rekindled through a histopathology study performed by Brownell and Hughes [3], who analyzed post mortem brain samples of twenty-two MS cases and systematically described the occurrence of MS lesions throughout the cerebrum. The authors found that $26 \%$ of the MS lesions were located in or around the cortical and subcortical GM. The high prevalence of demyelination in GM areas in MS was confirmed by a more recent study combining post mortem MRI and conventional histology data [4] and it was hypothesized that the distribution of cortical lesions might be causally related to vascular anatomy, which resulted in the definition of seven distinct types of cortical lesions (see Table 1). Later, another classification system was developed that distinguished between four major cortical lesion types, based on immunohistochemical detection of myelin [5,6]. It is this scoring system that is currently widely used for classification of cortical lesions in MS tissue.

Pathological hallmarks of cortical GM lesions seem to be largely restricted to demyelination and occasionally a minor microglial reaction. Thus, the pathology of cortical lesions strikingly differs from that of WM lesions. Lymphocyte infiltration, complement deposition, and bloodbrain barrier (BBB) disruption, all typical pathological hallmarks of WM lesions, are not usually found in cortical lesions [6-8]. Axonal transection, as well as neuronal, glial, and synaptic loss, may be found in a minority of cortical lesions [9,10]. A combination of demyelination and neuroaxonal degeneration probably best explains MRI reports of cortical atrophy and cortical thinning in MS [11-16], although the respective contributions of these processes to cortical volume loss have not yet been definitively determined [10,17]. A recent study described an overall cortical thickness reduction of approximately 10\% [10], which indicates that damage to the MS cortex may also occur outside of demyelinated lesions. Whether this 'global' cortical thinning is purely secondary to accumulating focal demyelination and neuroaxonal damage in the cortex, or whether substantial neuroaxonal loss may also occur independently of focal cortical lesions, i.e. in the 'normal-appearing' GM (NAGM), is so far not clear. Exactly which pathological process leads to cortical volume reduction in early disease $[12,14]$ is also unknown, as demyelination of axons in the cortex should still be relatively limited in those early stages [18]. Both MRI and histopathology studies have shown that GM pathology is already present in the earliest disease stages [12,18-21] (see also: Chard and Miller, this issue), but it becomes only prominent with progressive disease [15,18,22-25]. In chronic, progressive MS, cortical GM pathology, predominantly of the subpial type $[5,18,26]$, is accompanied by a more diffuse pathology in the WM, whereas the acute or early relapsing-remitting phase of the disease is mainly characterized by focal WM pathology [18]. Interestingly, a recent study comparing atrophy rates across the main MS clinical disease subtypes showed that, although the WM atrophy rate remained constant at threefold the normal rate across all disease stages, GM atrophy rate greatly accelerated in the secondary progressive phase [23]. This may be a reflection of rapidly accumulating demyelination and neuroaxonal damage in the GM as a result of, and perhaps in parallel with, damage to WM tracts (see next sections).

Demyelination within (cortical) GM areas may be of special importance to the clinical situation of the MS patient, since focal demyelination in the $\mathrm{WM}$, readily visible on magnetic resonance imaging (MRI), does not entirely explain the full array of clinical, including cognitive, deficits in MS [27]. WM lesion load, lesions in or around the cortex, and brain atrophy, as determined by MRI, may all explain part of the physical disability, epilepsy, depression, and global cognitive deterioration observed in MS [16,28-34]. However, some more specific cognitive deficits, such as memory impairment, which can be found in a large proportion of patients with MS [35], might be better explained by pathological processes (i.e., demyelination and possible resultant damage to the neurons) within GM structures. Although not a direct measure of cellular (dys)function, GM atrophy studies, as assessed by MRI, indeed showed that MS patients with cognitive decline had lower GM volumes than patients who were cognitively preserved $[36,37]$. Furthermore, a rarely occurring cortical variant of MS was

Table 1

proposed classification systems for cortical lesions [4,6].

\begin{tabular}{|c|c|}
\hline $\begin{array}{l}\text { Classification } \\
\text { according to Kidd }\end{array}$ & Cortical lesion distribution related to venous anatomy \\
\hline Cortical lesion type 1 & $\begin{array}{l}\text { Located in the deeper cortical laminae and subcortical white } \\
\text { matter; located within territory of the proximal branches of } \\
\text { the principal cortical vein (V5). }\end{array}$ \\
\hline Cortical lesion type 2 & $\begin{array}{l}\text { Affects all cortical layers, but without involving the underlying } \\
\text { subcortical white matter; Kidd-type } 2 \text { lesions may arise within } \\
\text { the territory of either V4/V5. }\end{array}$ \\
\hline Cortical lesion type 3 & $\begin{array}{l}\text { Usually extensive and located only in the superficial cortical } \\
\text { layers; may arise within territory of small superficial veins } \\
\text { originating from the central gyral vein (V1-V3), but may also } \\
\text { affect distal parts of V4 and V5. }\end{array}$ \\
\hline Cortical lesion type 4 & $\begin{array}{l}\text { Affects only the subcortical U-fibres; may be related to the } \\
\text { proximal end of the principal vein (V5). }\end{array}$ \\
\hline Cortical lesion type 5 & $\begin{array}{l}\text { Large cortical lesion affecting all cortical laminae and } \\
\text { subcortical white matter; distribution corresponds to the } \\
\text { territory of a principal vein. }\end{array}$ \\
\hline Cortical lesion type 6 & $\begin{array}{l}\text { Small cortical lesions, occurring in any part of the cortical } \\
\text { ribbon; lesion type may arise within territory of the small } \\
\text { branches of the larger perforating venous channels (V4 and } \\
\text { V5), but may also be within the territory of V1-V3. }\end{array}$ \\
\hline Cortical lesion type 7 & $\begin{array}{l}\text { Largest cortical lesion involving an entire gyrus, with or } \\
\text { without involvement of subcortical white matter; lesion may } \\
\text { arise within the territory of a series of V4 and V5 (principal) } \\
\text { veins, most likely affecting the collecting central vein. }\end{array}$ \\
\hline $\begin{array}{l}\text { Classification } \\
\text { according to Bö }\end{array}$ & Simplified topological description of cortical lesions \\
\hline Cortical lesion type 1 & $\begin{array}{l}\text { Mixed WM/GM lesion, more HLA-DR immunopositivity in } \\
\text { WM portion and, although less so, also in the GM portion of } \\
\text { the lesion. }\end{array}$ \\
\hline Cortical lesion type 2 & $\begin{array}{l}\text { Small, intracortical lesion, usually surrounding a blood vessel; } \\
\text { non-inflammatory. }\end{array}$ \\
\hline Cortical lesion type 3 & $\begin{array}{l}\text { Subpial cortical demyelination, reaching from the pia } \\
\text { downwards into the cortex. Does not reach the WM-GM } \\
\text { border. Can grow extensive; non-inflammatory. }\end{array}$ \\
\hline Cortical lesion type 4 & $\begin{array}{l}\text { Lesion covering the entire cortical span (from pia to WM-GM } \\
\text { border, though not crossing that border; non-inflammatory. }\end{array}$ \\
\hline
\end{tabular}




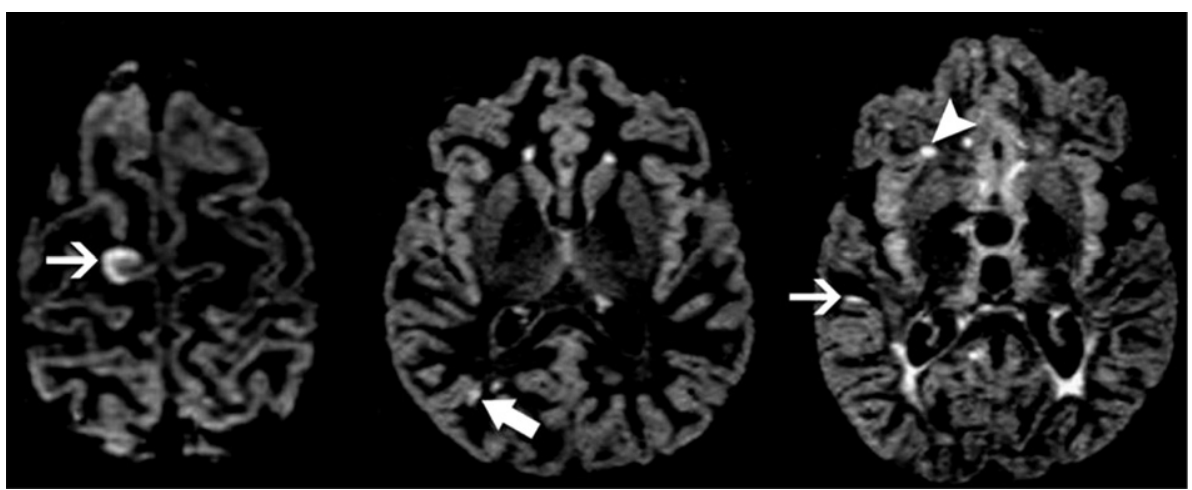

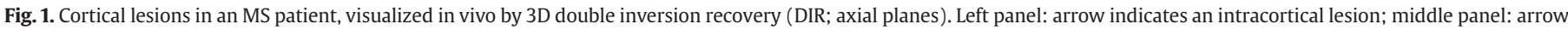
indicates a mixed WM-GM (Bö-type I) lesion; right panel: arrow indicates a juxtacortical lesion, arrowhead indicates a mixed WM-GM lesion.

proposed, with patients showing predominant or exclusive cognitive decline starting from disease onset $[38,39]$.

The most significant and meaningful clinicocognitive correlations might be obtained from an analysis of functional subsystems within the brain. In recent years, subcortical GM areas have been carefully explored using immunohistochemistry, and demyelination was found in the thalamus, basal ganglia, hypothalamus, hippocampus, cerebellum, and spinal cord [18,26,40-44]. Unlike intracortical lesions, hypothalamic - and to a lesser extent also - spinal cord GM lesions usually showed a stronger inflammatory profile, with presence of activated microglia or even actively demyelinating (foamy) macrophages. The pathological profile of hippocampal lesions resembled that of intracortical lesions, with the only prominent pathological feature being extensive demyelination without significant microglia activation. Whether these regional inflammatory differences are caused by variations in myelin density, in specific GM constituents, or e.g. by regional differences in the duration of the inflammatory demyelinating phase, is hitherto unclear. Hippocampal lesions were reported to be surprisingly common in chronic MS autopsy cases (two to three hippocampal lesions per patient on average [41]), and these could be related to memory impairment upon retrospective chart analysis. Recent MRI work, utilizing the same 3D double inversion recovery (DIR) method that was previously applied to improve detection of cortical lesions in MS [33,45], showed that hippocampal lesions can be visualized in vivo, yielding similar average lesion numbers as reported before in the post mortem setting [46]. With these imaging techniques and this expertise now available, the clinical effects of MS lesions within functional subsystems such as the hippocampal formation can now be studied in a more straightforward fashion.

\section{Advanced imaging techniques used to visualize GM damage}

As mentioned, the problem of low conspicuity of cortical GM lesions on conventional MR images was partly solved by the introduction of the DIR technique (see Fig. 1), which showed a fivefold improvement of cortical lesion detection compared to standard T2-weighted MRI [45]. Furthermore, 3D T1-based imaging [47], and a combination of phase-sensitive inversion recovery and DIR [48], were successfully applied to enhance the visualization of GM lesions in MS. Whether all, or at least most of, the cortical GM lesions can be detected by these new techniques remains to be elucidated. This question can only be truly answered in a post mortem study directly comparing MR imaging to myelin immunohistochemical stainings of the MS cortex. The application of higher field-strengths may equally be beneficial in terms of improving cortical lesion detection in MS [49], although this critically depends on the choice of
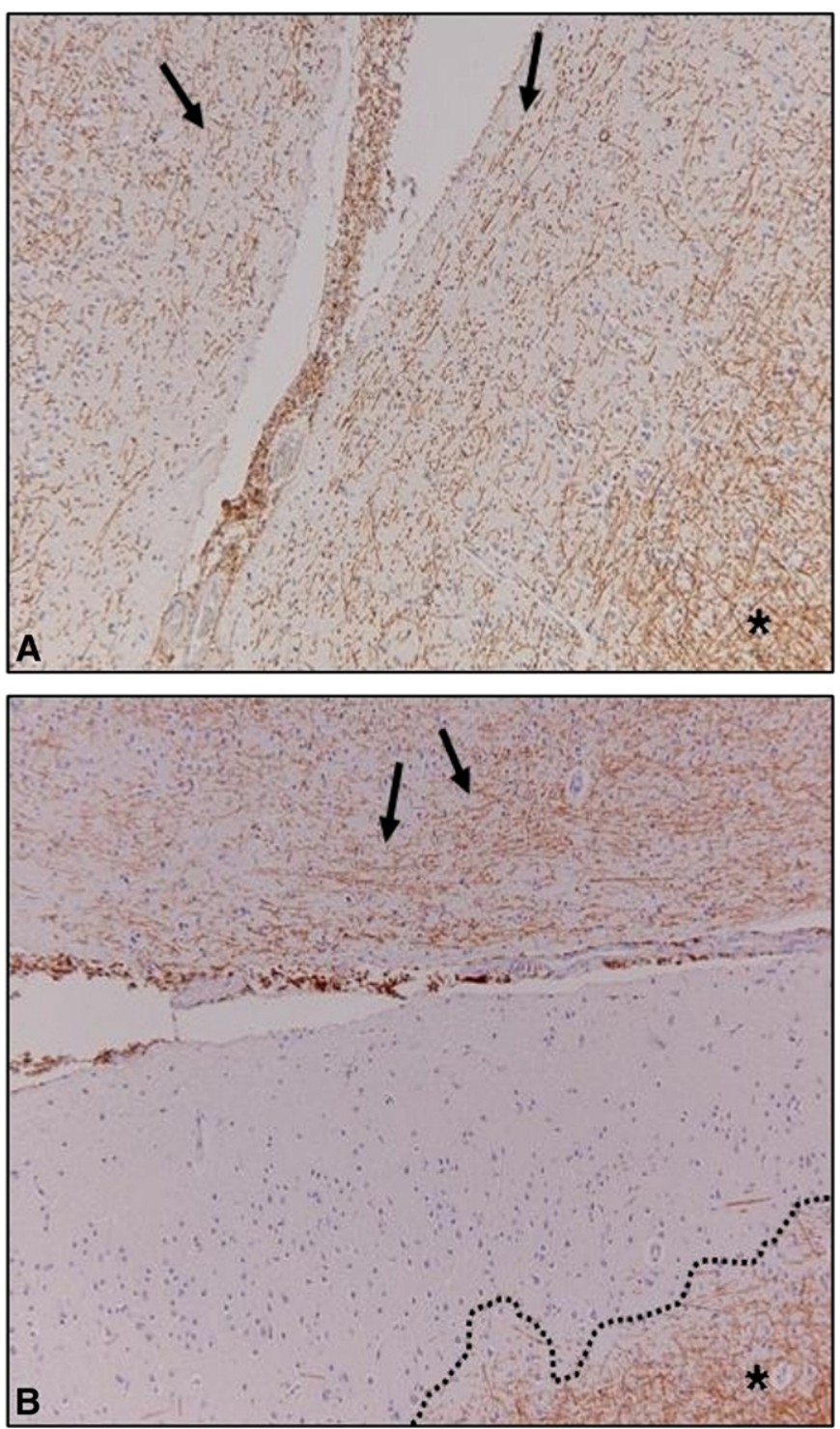

Fig. 2. The upper layers of the human cortex are intrinsically sparsely myelinated (arrows in A and B), compared to the lower cortical layers (asterisks); therefore, in case of subpial demyelination in MS ( $B$; lesion border outlined by the dotted line), and due to the lack of inflammation, relatively little contrast is generated, which probably explains the low conspicuity of these subpial lesions on MRI. 
parameters [50]. When attempting to visualize subpial cortical demyelination for example, spatial resolution improvements may be best traded off to some extent for a higher signal-to-noise, as subpial lesions are generally not that small but do generate very low contrast due to the inherently low myelin densities in the upper layers of the cortex (Fig. 2).

Besides visualization of cortical lesions, in vivo GM pathology has also been assessed by measuring the NAGM, using advanced quantitative MRI techniques like diffusion tensor (DT) imaging, T1or T2-relaxometry, magnetization transfer imaging (MTI), and (proton) MR spectroscopy (MRS). These techniques have been reported to be more sensitive to pathology in the GM than conventional MRI sequences, but they generally have a poorer spatial resolution, which makes it difficult to distinguish between lesional and non-lesional GM. Abnormalities that have been reported with MTR [51,52], T1-relaxation time measurements [53,54], DTI [55,56], and proton MRS $[57,58]$ within cortical and subcortical GM in MS, may therefore reflect demyelinated lesions mainly, although it cannot be ruled out at this point that a more diffuse and subtle damage in the non-lesional 'normal-appearing' GM is picked up on, as well. The relationship between cortical lesions and (regional) cortical atrophy or cortical thinning in MS is so far largely unclear. Still, cortical volume or thickness reductions correlating with clinical deficits have been consistently reported in MS patients, with a relative predominance in frontotemporal areas [11-13,23,59-61].

It should be noted that structural damage need not always lead to clinical abnormalities. Recent functional MRI studies have shown differences in brain activation between MS patients and controls. Functional cortical changes were found in response to motor tasks and as a result of accumulating WM lesions [62]. These functional changes were strongly correlated with axonal damage as measured by proton
MRS [63], and with damage in normal-appearing brain tissue as measured by MTI and DTI $[64,65]$. Functional cortical changes were also found in relation to cognitive processing $[66,67]$ even at the earliest stage of disease [68]. In addition to the brain, functional compensatory changes were detected in the cervical spinal cord of MS patients, which may or may not result in a bypassing of the clinical consequences of irreversible tissue damage in MS [69,70]. As GM demyelination is prominent in the spinal cord [44], and spinal cord GM lesions may be slightly more easy to visualize with MRI than cortical GM lesions [50,71], the spinal cord makes an interesting additional target for studying functional adaptations following GM damage.

At present, several challenges remain within the field of GM pathology in MS. Improving the visualization of GM lesions with new (combinations of) MRI methods remains important, and high-end imaging studies combining measures of functional and structural damage may be expected to improve our understanding of the clinical reflection of GM pathology in MS. This approach should narrow down the discrepancy between the observed daily functioning of MS patients and the abnormalities visible on their MRIs. Another important challenge for the years ahead is to create more understanding of the pathogenetic mechanisms underlying GM damage in MS. With this knowledge at hand, we may then be able to develop a more targeted treatment for the neurodegenerative aspects of the disease.

\section{Pathogenic mechanisms possibly leading to GM damage}

Although the exact pathological mechanisms underlying neurodegeneration are presently unknown, it is often considered to be secondary to myelin damage. In this so-called 'outside-in' model,

A
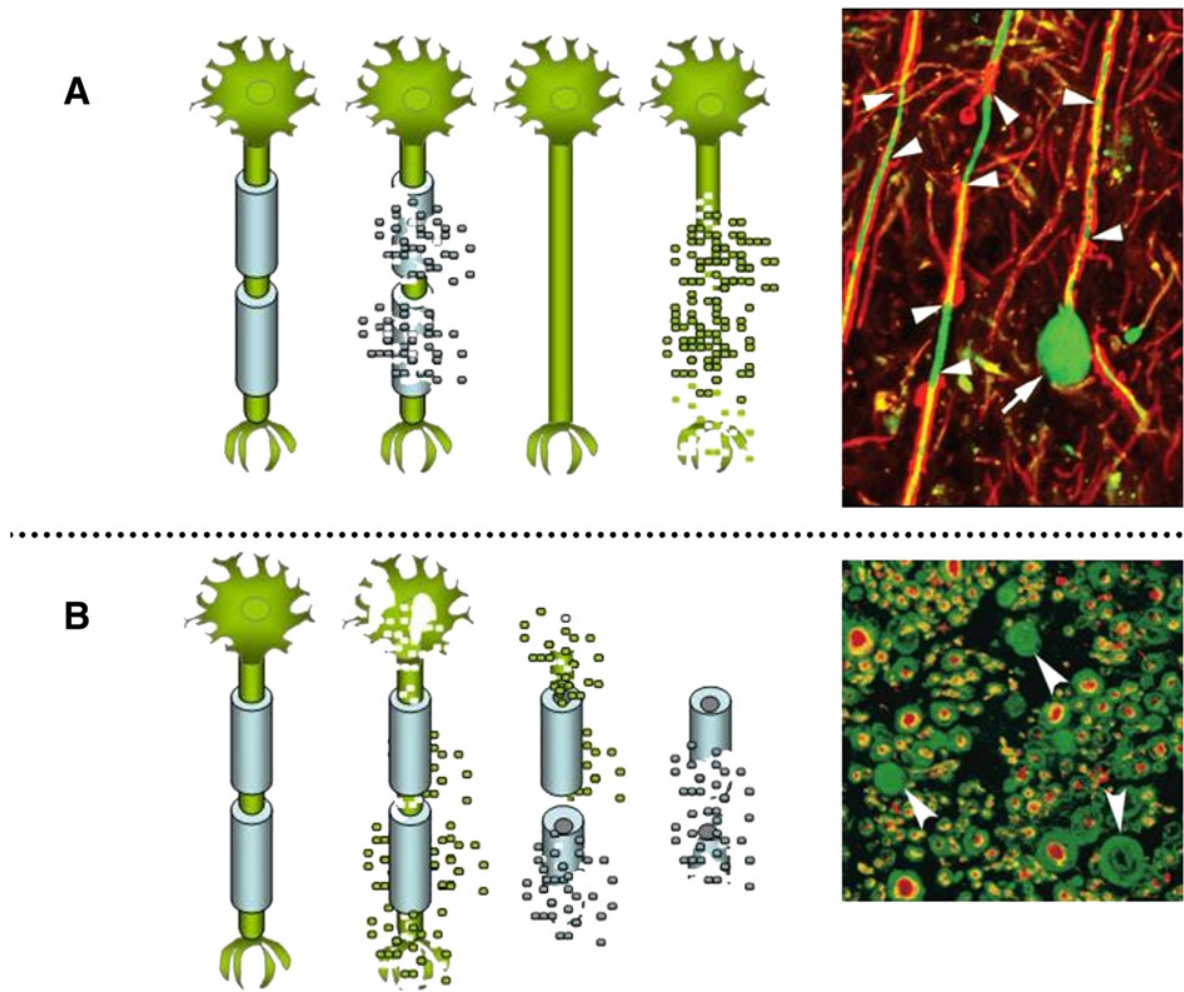

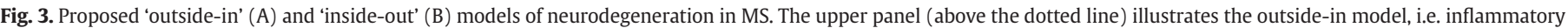

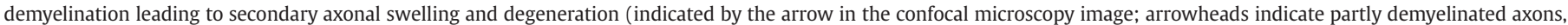

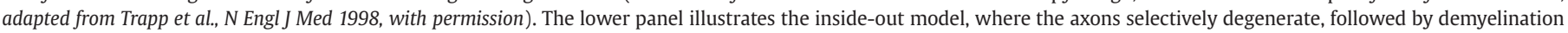

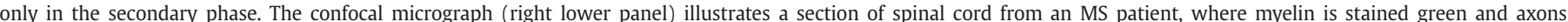

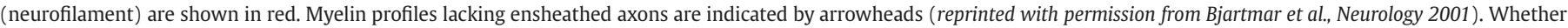

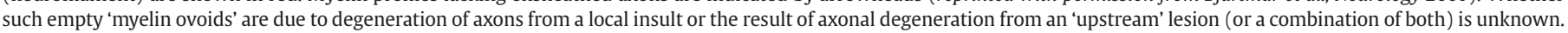
It is highly likely that both outside-in and inside-out pathogenetic mechanisms play a role in MS (see text). 
damage first occurs to the 'outer unit' i.e. oligodendrocyte or the myelin membranes, and as a result of the demyelination, the 'inside unit', i.e. the axon, becomes vulnerable and degenerates with time (Fig. 3A).

However, axonal injury may also precede demyelination in MS, in which case neurodegeneration may be caused by specific insults to axons or neurons. Such a 'direct attack' may induce axonal retraction and thus empty myelin sheaths, which then degenerate secondarily. Thus, in this so called 'inside-out' model, damage to the axon (inside) leads to loss of myelin (outside) - (Fig. 3B) [72].

\subsection{The outside-in model}

Different pathological mechanisms may underlie primary demyelination in MS, as was shown by the study of other demyelinating diseases in humans and animals, as well as by experimental infections and experimental autoimmune disorders, particularly autoimmune encephalomyelitis (EAE; an autoimmune model of MS induced in susceptible animals following immunization with myelin antigens). Demyelination in both humans and rodents is observed following viral infections through a wide range of mechanisms [73]. These include lytic infections of oligodendrocytes, bystander demyelination whereby the inflammatory response to virally infected cells (other than oligodendrocytes) mediates damage to oligodendrocytes and myelin, the phenomenon of 'molecular mimicry' in which common peptide epitopes on the virus and myelin activate an autoimmune response, or - as a consequence of one or more of these events stimulation of a pathogenic autoimmune response by myelin debris.

Although many viruses have been implicated in MS, including those known to induce myelin damage, it is still unknown whether a single virus or several viruses are involved. The only virus that has been reliably linked with MS in epidemiological studies so far is the Epstein-Barr virus (EBV). In a recent study [74], the risk for MS was significantly increased in patients with infectious mononucleosis - an EBV related disease - compared to patients with other common childhood infections. How EBV is involved in the disease is as yet unclear, although infection of B-cells and subsequent autoantibody production may be one of the mechanisms leading to myelin damage in the cortical GM in MS. One such mechanism could be the immortalisation of B-cells secreting CNS reactive antibodies [75]. Indeed, EBV positive B-cells have been reported in the meninges of MS patients [76], although it remains to be seen if indeed they do secrete pathogenic CNS specific autoantibodies and hence induce subpial cortical demyelination in MS. A recent report investigated the relationship between the levels of anti-EBV antibodies and quantitative MRI outcomes in MS patients [77]. In that study, higher anti-EBVVCA IgG antibody levels were associated with lower values of GM fraction and brain parenchymal fraction (BPF). Increased levels of anti-EBV VCA IgG at baseline were associated with increased loss of BPF over 3-year follow-up. These results indicate that EBV-mediated immune dysfunction could be (causally) involved in GM damage in MS.

The idea that autoantibodies to myelin antigens may be pathogenically involved in MS comes from studies in rodent EAE $[78,79]$. While myelin-specific CD4+ T-cells were once thought crucial for EAE in mice, attention has shifted towards the role of MHC class I restricted CD8+ T-cells and the role of autoreactive antibodies directed to myelin as well as neurons. It is well known that neurological disease in EAE is dependent on MHC class II restricted CD4+ T-cells, although CD8 + cells have also been shown to induce disease [80]. Nevertheless, extensive myelin damage is only observed following co-injection with antibodies directed to myelin oligodendrocyte glycoprotein (MOG), an antigen on the surface of myelin [81]. In addition, immunization of mice with MOG-deficient myelin does not lead to chronic relapsing disease and myelin damage [82], probably due to the absence of autoantibodies to MOG. Although further studies are necessary to elucidate the presence of pathogenic antibodies in patients since data so far are conflicting [83], it can be envisaged that autoantibodies directed to myelin, or indeed neurons, may be responsible in part for grey matter demyelination and possible subsequent damage to the neuropil in MS [79,84].

Regardless of the pathological mechanism, oligodendrocytes do show signs of stress in MS, as well as in EAE. In MS, peroxynitrite [85] and nitric oxide [86] are consistently associated with active WM lesions and lead to the production of nitrating and oxidizing radical species that alter lipid, protein, DNA and mitochondrial structure and function. That such hypoxia-like tissue damage may be due to mitochondrial impairment comes from studies comparing MS damage with WM stroke, in which defects in the mitochondrial respiratory chain complex IV were detected in some forms of MS [87]. Together with hypoxic histopathology that is often [88], but not invariably [89], detected at the level of the oligodendrocyte in MS lesions, these observations argue in favor of oligodendrocyte/myelin injury that may be partly independent of the immune assault. The question now is, how might demyelination predispose an axon to degeneration? One can divide the axon-supportive role of myelin into two broad categories. First is the known 'trophic signalling' by myelin-associated proteins that support the structural integrity of the ensheathed axon. This signalling is complex and is only beginning to be understood with the aid of transgenic animal models exhibiting mutated myelin proteins (for a recent review see [90]). For instance, shiverer mice, harbouring a defect in the gene encoding myelin basic protein, are severely dysmyelinated in the CNS, and exhibit significant axonal degeneration [91-93]. One may reasonably conclude that simply the absence of ensheathing myelin is detrimental to the axon, by virtue of reduced trophic signalling or disadvantageous energetics (see below). In reality the situation is more complex because for instance, Plp1 null mice, completely lacking proteolipid protein, which is a major myelin constituent, have normally myelinated CNS tracts. These animals then develop a late-onset axonal degeneration, characterized by axonal swellings and Wallerian degeneration in fibers that are seemingly still normally myelinated [93]. Taken together, such observations clearly implicate myelin as a key player in maintaining axonal integrity, but not just by the passive act of ensheathing a fiber. The second major influence of myelin on its axon concerns the energy savings realized by saltatory action potential conduction. Demyelinated axons frequently have their $\mathrm{Na}^{+}$channels distributed more homogeneously along the denuded axolemma [94]. The potential advantage is that this adaptation may continue to support action potential propagation, but at the cost of increased energy requirement; due to the larger capacitance and lower resistance of the demyelinated axon segments, far more charge (i.e., ions) is needed to support electrogenesis. In turn, these additional $\mathrm{Na}^{+}$and $\mathrm{K}^{+}$ions must be transported back up their electrochemical gradients, potentially greatly increasing the energy demands on the axon. Thus, from an energetics argument, the loss of the insulating myelin sheath may indirectly contribute to an axonal energy deficit, and ultimately, to axonal degeneration.

\subsection{The inside-out model}

The observations provided in the previous section provide compelling arguments for why an intact (structurally and genetically) myelin sheath is essential for axonal health. However, the axon may also be disadvantaged directly, by the abnormal environment known to be present in inflammatory lesions (and possibly in normal-appearing WM as well). A recent MRI study demonstrated that some alleles within the HLA class II region are associated with a lower GM fraction and a higher WM T1 lesion volume, both indicative of more pronounced neuroaxonal loss in patients with this particular genetic background [95]. Furthermore, defects in mitochondrial function are known to exist in brains of MS patients [87,96]. Although the mechanisms are unclear, it can be expected that mutation in genes encoding for mitochondrial proteins 
may underlie some forms of MS since MS-like features are observed in Leber's hereditary optic neuropathy and autosomal dominant optic neuropathy [97]. In an interesting recent study by Dutta et al. [96], gene expression levels of post mortem MS cortex were compared with controls and it was found that twenty-six nuclear-encoded mitochondrial genes and the functional activities of mitochondrial respiratory chain complexes I and III were decreased in MS cortical neurons. These same mitochondria are transported into projecting axons, and therefore it is likely that the axons also are subjected to a relatively energy deficient state as a result of defects in these key energy-producing organelles. Moreover, production of substantial quantities of NO (which is then converted to an even more toxic by-product, peroxynitrite) in an inflammatory milieu, may further compromise mitochondrial function by interference with mitochondrial electron transport $[85,86]$. This abnormal mitochondrial functioning, leading to reduced cellular ATP production, in combination with an increased energy demand of the axon (previous section), leads to a state of what has been termed 'virtual hypoxia' [98].

Another potential key signalling pathway that may play a very important role in direct axonal injury involves ionotropic $[99,100]$ and metabotropic glutamate receptors (GluRs) [101,102]. Glutamate levels are elevated in the brains of MS patients, and in the CSF in patients with active disease [103,104]. To make matters worse, glutamate transport capacity (normally functioning to sequester glutamate into the intracellular compartment to prevent extracellular concentrations from rising to toxic levels) and glutamate degrading enzymes are reduced in MS lesions [105]. Coupled with the known ability of inflammatory cells to release potentially large quantities of glutamate, neuroinflammatory lesions are prone to promoting excitotoxic damage to elements that express relevant receptors. Very recent data have revealed the presence of AMPA and kainate (but not NMDA) receptors on the internodal axolemma of central myelinated axons [106]. Activation of ionotropic GluRs is known to be very damaging to central white matter tracts (for a review see: [107]), especially when they are simultaneously exposed to even sublethal levels of energy deprivation [108]. We can now be fairly certain that a substantial component of this excitotoxic structural and functional WM damage is due to direct activation of axonal GluRs. Axons have the added disadvantage of containing large quantities of $\mathrm{Ca}^{2+}$ stored in their endoplasmic reticulum cisternae ('axoplasmic reticulum'). Depolarization, which occurs under energy-limited conditions or conditions of impaired ion pumping (see below), releases damaging amounts of this stored $\mathrm{Ca}^{2+}$, leading to permanent axonal injury [109]. Intriguing are recent observations linking axonal AMPA and kainate receptors to these intra-axonal $\mathrm{Ca}^{2+}$ stores [106]; moreover, this pathway is under additional control of NO synthesized locally by axonal nNOS [104]. Thus, GluRs, nNOS, voltage-gated $\mathrm{Ca}^{2+}$ channels, and intracellular $\mathrm{Ca}^{2+}$ release channels (ryanodine and IP3 receptors) are arranged in various combinations along the internodal axolemma in multimolecular 'nanocomplexes', capable of releasing toxic amounts of intracellular $\mathrm{Ca}^{2+}$ that can irreversibly damage an axon. Unfortunately for axons coursing through MS lesions, these $\mathrm{Ca}^{2+}$-sourcing nanocomplexes are under the control of glutamate and $\mathrm{NO}$, and both substances are likely present in abnormally high concentrations in lesions. Finally, recent data indicate that the key ion-pumping ATPase normally present at high densities on the intermodal axolemma (Na-K-ATPase) is reduced by more than $50 \%$ in chronic lesions [110]. This limited capacity to translocate $\mathrm{Na}^{+}$and $\mathrm{K}^{+}$ ions, particularly in the face of an increased ionic load per action potential because of demyelinated internodes (see previous section), implies depolarized and $\mathrm{Na}^{+}$-loaded axons. This in turn would activate the $\mathrm{Ca}^{2+}$ sourcing nanocomplexes, impair the tissue's ability to buffer glutamate, further exacerbating the vicious cycle of biochemical injury, and likely tipping the axon past the point of no return, and towards permanent degeneration.

The question is: where does it all start? Could it be that the axon is the primary target, with myelin degenerating only secondarily? Most likely, neither the 'inside-out' (axon first) nor the 'outside-in' (myelin first) mechanisms operate exclusively, nor independently. Rather, it is highly likely that both mechanisms operate to damage their respective elements, with the results only feeding and further driving the deleterious cascades promoting even more injury in a feed-forward manner. If this is indeed the case, it implies that the 'gain' of the injury cascades is high, so that minor perturbations in the fine balance between axo-glial health and pathology can tip the system into relentless degeneration. On the other hand, such a 'high-gain' arrangement may be amenable to fine and robust control and restraint. The challenge is to identify the key control points in the ever more complex series of events leading to axonal degeneration (please refer to [111] for a recent review discussing the various pathways and possibilities for therapeutic intervention in greater depth).

Finally, besides the question what initiates an MS lesion, the apparent restrictedness or focality of GM and WM lesions is intriguing: where and why does the lesion stop? Understanding what happens at the barrier between lesional and healthy tissue may be equally or even more important in the development of a successful therapeutic approach.

\section{Imaging neurodegeneration in a therapeutic setting: do we have a valid technique?}

Multi-focal WM lesions, brain atrophy and, to a lesser extent, the more subtle changes in NAWM and NAGM can all be used as MRI outcome measures in MS. However, if we wish to monitor GM damage and the neurodegenerative aspects of MS in a clinical trial setting, measurement of brain atrophy may be the most relevant biomarker [112].

It should be noted that the terms 'brain atrophy' and 'brain volume (BV) loss' are not clearly distinct in the MS literature. Measured changes in BV in MS can be caused by two mechanisms [112]. Firstly, by changes in the degree of brain oedema that is associated with inflammation. Secondly, it may be caused by actual tissue loss (including loss of oligodendrocytes, myelin, axons and possibly also astrocytes), or increases in BV could be due to tissue regeneration (such as remyelination). Focal oedema in new lesions may mask reductions in BV caused by true atrophy, especially in those WM areas where inflammation is most pronounced. Massive cortical demyelination and a diffuse axonal loss in the NAWM contributing to loss of BV are present in the later stages of MS [18,113].

Dynamic changes in BV in MS can be considered a composite of volume-gaining and volume-losing processes that are influenced by the extent of inflammatory, neurodegenerative and remyelinating processes, potency of anti-inflammatory therapy, and its neuroprotective effects. One problem with every anti-inflammatory drug used in patients with MS is that they decrease whole BV more rapidly in the treated versus the placebo group due to reduced inflammation in the first couple of months of treatment [112]. The result is that none of the disease-modifying treatments (DMT) shows efficacy in preventing BV loss when the treatment vs. the placebo group are compared in the first year, with any beneficial effect only becoming evident in the second year and beyond. This accelerated treatment-related BV reduction was named pseudoatrophy [112]. At this point, it is not clear whether pseudoatrophy is inseparable from true BV decline or represents only accelerated water loss (fluid shifts) with no associated loss of cell structures. Also, it is not yet elucidated whether this is a temporary phenomenon. In fact, a recent study that investigated whether the acute brain BV loss following immunoablation and autologous hematopoietic stem cell transplantation (AHSCT) for MS is associated with a loss of myelin, water, or axons found no association between loss of BV and change in parenchymal water [114].

Furthermore, it is unknown whether the pseudoatrophy effect may affect different brain tissue classes (GM versus WM) at various rates, and whether it can be influenced by using different methods of BV 
measurement (direct versus indirect measurement of BV). Using data from the Avonex-Steroids-Azathioprine combination study [15], it was recently investigated whether GM volume is less susceptible to pseudoatrophy effects than whole BV or WM volume [115] and it was found that GM volume seems to be less susceptible to pseudoatrophy effects than WM volume or whole BV. Hence, GM volume change may be a more reliable marker to distinguish disease- and treatmentrelated BV changes.

At the moment, application of GM volume measurements and other GM-based non-conventional MRI techniques (MTR, DTI and MRS) in a clinical trial setting is not common practice. However, these techniques may become important outcome measures in the future. Their value in showing detectable drug-related changes over time is subject to further investigation. A preliminary study with intramuscular interferon beta-1a showed a slowing of progression of whole brain atrophy predominantly by reducing the GM atrophy component in relapsing-remitting MS [116]. Further studies are needed to establish whether measurement of GM volumes may become a reliable outcome measure for MS clinical trials, especially trials focusing on the neurodegenerative aspects of the disease.

\section{Conclusions}

GM pathology already occurs early in MS and accumulates substantially with progressing disease. What causes GM pathology, and why GM damage accelerates after conversion to the secondary progressive phase, is so far largely unknown. Several pathogenic mechanisms might play a role, and both 'outside-in' and 'inside-out' types of pathogenesis have been suggested. In the outside-in model, the myelin is primarily affected followed by degeneration of the neuroaxonal structures; in the 'inside out' pathology, the neuroaxonal structures primarily degenerate, followed by secondary degeneration of the myelin sheaths. GM damage in MS may well be caused by a combination of these proposed mechanisms. Clinically, GM damage is of relevance to MS patients, especially where cognitive impairment is concerned. With respect to emerging neuroprotective trials, GM atrophy measurements are presently expected to be the most reliable MRI monitoring tool, although this may change in the future with the development of new MRI methods for detecting GM abnormalities more sensitively.

\section{Acknowledgements}

JJGG is financially supported by the Dutch MS Research Foundation (grant no. 05-358c). The authors wish to thank Drs. S.D. Roosendaal and E.-J. Kooi for help with Figs. 1 and 2, and Drs. B.D. Trapp and G. Kidd for help with Fig. 3.

\section{References}

[1] McHenry LC. Garrison's history of neurology; 1969. p. 278-82.

[2] Dawson JW. The histology of multiple sclerosis. Trans R Soc Edinburgh 1916;50:517-740.

[3] Brownell B, Hughes JT. The distribution of plaques in the cerebrum in multiple sclerosis. J Neurol Neurosurg Psychiatry 1962;25:315-20.

[4] Kidd D, Barkhof F, McConnell R, Algra PR, Allen IV, Revesz T. Cortical lesions in multiple sclerosis. Brain 1999;122(Pt 1):17-26.

[5] Bo L, Vedeler CA, Nyland HI, Trapp BD, Mork SJ. Subpial demyelination in the cerebral cortex of multiple sclerosis patients. J Neuropathol Exp Neurol 2003;62: 723-32.

[6] Bo L, Vedeler CA, Nyland H, Trapp BD, Mork SJ. Intracortical multiple sclerosis lesions are not associated with increased lymphocyte infiltration. Mult Scler 2003;9:323-31.

[7] Brink BP, Veerhuis R, Breij EC, van der Valk P, Dijkstra CD, Bo L. The pathology of multiple sclerosis is location-dependent: no significant complement activation is detected in purely cortical lesions. J Neuropathol Exp Neurol 2005;64: 147-55.

[8] van Horssen J, Brink BP, de Vries HE, van der Valk P, Bo L. The blood-brain barrier in cortical multiple sclerosis lesions. J Neuropathol Exp Neurol 2007;66: 321-8.

[9] Peterson JW, Bo L, Mork S, Chang A, Trapp BD. Transected neurites, apoptotic neurons, and reduced inflammation in cortical multiple sclerosis lesions. Ann Neurol 2001;50:389-400.
[10] Wegner C, Esiri MM, Chance SA, Palace J, Matthews PM. Neocortical neuronal, synaptic, and glial loss in multiple sclerosis. Neurology 2006;67:960-7.

[11] Sailer M, Fischl B, Salat D, Tempelmann C, Schonfeld MA, Busa E, et al. Focal thinning of the cerebral cortex in multiple sclerosis. Brain 2003;126:1734-44.

[12] De Stefano N, Matthews PM, Filippi M, Agosta F, De Luca M, Bartolozzi ML, et al. Evidence of early cortical atrophy in MS: relevance to white matter changes and disability. Neurology 2003;60:1157-62.

[13] Chen JT, Narayanan S, Collins DL, Smith SM, Matthews PM, Arnold DL. Relating neocortical pathology to disability progression in multiple sclerosis using MRI Neuroimage 2004;23:1168-75.

[14] Sepulcre J, Sastre-Garriga J, Cercignani M, Ingle GT, Miller DH, Thompson AJ. Regional gray matter atrophy in early primary progressive multiple sclerosis: a voxel-based morphometry study. Arch Neurol 2006;63:1175-80.

[15] Horakova D, Cox JL, Havrdova E, Hussein S, Dolezal O, Cookfair D, et al. Evolution of different MRI measures in patients with active relapsing-remitting multiple sclerosis over 2 and 5 years: a case-control study. J Neurol Neurosurg Psychiatry 2008;79:407-14.

[16] Benedict RH, Bruce JM, Dwyer MG, Abdelrahman N, Hussein S, WeinstockGuttman B, et al. Neocortical atrophy, third ventricular width, and cognitive dysfunction in multiple sclerosis. Arch Neurol 2006;63:1301-6.

[17] Pomeroy IM, Jordan EK, Frank JA, Matthews PM, Esiri MM. Diffuse cortical atrophy in a marmoset model of multiple sclerosis. Neurosci Lett 2008:437:121-4.

[18] Kutzelnigg A, Lucchinetti CF, Stadelmann C, Bruck W, Rauschka H, Bergmann M, et al. Cortical demyelination and diffuse white matter injury in multiple sclerosis. Brain 2005; $128: 2705-12$.

[19] Audoin B, Davies G, Rashid W, Fisniku L, Thompson AJ, Miller DH. Voxel-based analysis of grey matter magnetization transfer ratio maps in early relapsing remitting multiple sclerosis. Mult Scler 2007;13:483-9.

[20] Chard DT, Griffin CM, Rashid W, Davies GR, Altmann DR, Kapoor R, et al. Progressive grey matter atrophy in clinically early relapsing-remitting multiple sclerosis. Mult Scler 2004;10:387-91.

[21] Khaleeli Z, Cercignani M, Audoin B, Ciccarelli O, Miller DH, Thompson AJ. Localized grey matter damage in early primary progressive multiple sclerosis contributes to disability. Neuroimage 2007;37:253-61.

[22] Oreja-Guevara C, Rovaris M, Iannucci G, Valsasina P, Caputo D, Cavarretta R, et al Progressive gray matter damage in patients with relapsing-remitting multiple sclerosis: a longitudinal diffusion tensor magnetic resonance imaging study. Arch Neurol 2005;62:578-84.

[23] Fisher E, Lee JC, Nakamura K, Rudick RA. Gray matter atrophy in multiple sclerosis: a longitudinal study. Ann Neurol 2008;64:255-65.

[24] Fisniku LK, Chard DT, Jackson JS, Anderson VM, Altmann DR, Miszkiel KA, et al. Gray matter atrophy is related to long-term disability in multiple sclerosis. Ann Neurol 2008;64:247-54.

[25] Geurts JJ. Is progressive multiple sclerosis a gray matter disease? Ann Neurol 2008;64:230-2.

[26] Geurts JJ, Bo L, Pouwels PJ, Castelijns JA, Polman CH, Barkhof F. Cortical lesions in multiple sclerosis: combined postmortem MR imaging and histopathology. AJNR Am J Neuroradiol 2005;26:572-7.

[27] Barkhof F. The clinico-radiological paradox in multiple sclerosis revisited. Curr Opin Neurol 2002:15:239-45.

[28] Moriarty DM, Blackshaw AJ, Talbot PR, Griffiths HL, Snowden JS, Hillier VF, et al. Memory dysfunction in multiple sclerosis corresponds to juxtacortical lesion load on fast fluid-attenuated inversion-recovery MR images. AJNR Am J Neuroradiol 1999;20:1956-62.

[29] Lazeron RH, Langdon DW, Filippi M, van Waesberghe JH, Stevenson VL, Boringa $\mathrm{JB}$, et al. Neuropsychological impairment in multiple sclerosis patients: the role of (juxta)cortical lesion on FLAIR. Mult Scler 2000;6:280-5.

[30] Rovaris M, Filippi M, Minicucci L, Iannucci G, Santuccio G, Possa F, et al. Cortical/ subcortical disease burden and cognitive impairment in patients with multiple sclerosis. AJNR Am J Neuroradiol 2000;21:402-8.

[31] Feinstein A, Roy P, Lobaugh N, Feinstein K, O'Connor P, Black S. Structural brain abnormalities in multiple sclerosis patients with major depression. Neurology 2004;62:586-90.

[32] Sokic DV, Stojsavljevic N, Drulovic J, Dujmovic I, Mesaros S, Ercegovac M, et al. Seizures in multiple sclerosis. Epilepsia 2001;42:72-9.

[33] Calabrese M, De Stefano N, Atzori M, Bernardi V, Mattisi I, Barachino L, et al. Detection of cortical inflammatory lesions by double inversion recovery magnetic resonance imaging in patients with multiple sclerosis. Arch Neurol 2007;64: 1416-22.

[34] Calabrese M, De SN, Atzori M, Bernardi V, Mattisi I, Barachino L, et al. Extensive cortical inflammation is associated with epilepsy in multiple sclerosis. J Neuro 2008;255:581-6.

[35] Rao SM. Neuropsychology of multiple sclerosis. Curr Opin Neurol 1995;8:216-20.

[36] Amato MP, Bartolozzi ML, Zipoli V, Portaccio E, Mortilla M, Guidi L, et al. Neocortical volume decrease in relapsing-remitting MS patients with mild cognitive impairment. Neurology 2004;63:89-93.

[37] Amato MP, Portaccio E, Goretti B, Zipoli V, Battaglini M, Bartolozzi ML, et al. Association of neocortical volume changes with cognitive deterioration in relapsing-remitting multiple sclerosis. Arch Neurol 2007;64:1157-61.

[38] Zarei M, Chandran S, Compston A, Hodges J. Cognitive presentation of multiple sclerosis: evidence for a cortical variant. J Neurol Neurosurg Psychiatry 2003;74: 872-7.

[39] Zarei M. Clinical characteristics of cortical multiple sclerosis. J Neurol Sci 2006;245:53-8.

[40] Kutzelnigg A, Faber-Rod JC, Bauer J, Lucchinetti CF, Sorensen PS, Laursen H, et al. Widespread demyelination in the cerebellar cortex in multiple sclerosis. Brain Pathol 2007;17:38-44. 
[41] Geurts JJ, Bo L, Roosendaal SD, Hazes T, Daniels R, Barkhof F, et al. Extensive hippocampal demyelination in multiple sclerosis. J Neuropathol Exp Neurol 2007;66:819-27.

[42] Vercellino M, Plano F, Votta B, Mutani R, Giordana MT, Cavalla P. Grey matter pathology in multiple sclerosis. J Neuropathol Exp Neurol 2005;64:1101-7.

[43] Huitinga I, De Groot CJ, van der Valk P, Kamphorst W, Tilders FJ, Swaab DF. Hypothalamic lesions in multiple sclerosis. J Neuropathol Exp Neurol 2001;60:1208-18.

[44] Gilmore CP, Bo L, Owens T, Lowe J, Esiri MM, Evangelou N. Spinal cord gray matter demyelination in multiple sclerosis-a novel pattern of residual plaque morphology. Brain Pathol 2006;16:202-8.

[45] Geurts JJ, Pouwels PJ, Uitdehaag BM, Polman CH, Barkhof F, Castelijns JA Intracortical lesions in multiple sclerosis: improved detection with $3 \mathrm{D}$ double inversion-recovery MR imaging. Radiology 2005;236:254-60.

[46] Roosendaal SD, Moraal B, Vrenken H, Castelijns JA, Pouwels PJ, Barkhof F, et al. In vivo MR imaging of hippocampal lesions in multiple sclerosis. J Magn Reson Imaging 2008;27:726-31.

[47] Bagnato F, Butman JA, Gupta S, Calabrese M, Pezawas L, Ohayon JM, et al. In vivo detection of cortical plaques by MR imaging in patients with multiple sclerosis. AJNR Am J Neuroradiol 2006;27:2161-7.

[48] Nelson F, Poonawalla AH, Hou P, Huang F, Wolinsky JS, Narayana PA. Improved identification of intracortical lesions in multiple sclerosis with phase-sensitive inversion recovery in combination with fast double inversion recovery MR imaging. AJNR Am J Neuroradiol 2007;28:1645-9.

[49] Kangarlu A, Bourekas EC, Ray-Chaudhury A, Rammohan KW. Cerebral cortica lesions in multiple sclerosis detected by MR imaging at 8 Tesla. AJNR Am J Neuroradiol 2007;28:262-6.

[50] Geurts JJ, Blezer EL, Vrenken H, van der TA, Castelijns JA, Polman CH, et al. Does highfield MR imaging improve cortical lesion detection in multiple sclerosis? J Neurol 2008;255:183-91.

[51] Cercignani M, Bozzali M, Iannucci G, Comi G, Filippi M. Magnetisation transfer ratio and mean diffusivity of normal appearing white and grey matter from patients with multiple sclerosis. J Neurol Neurosurg Psychiatry 2001:70:311-7.

[52] Ramio-Torrenta L, Sastre-Garriga J, Ingle GT, Davies GR, Ameen V, Miller DH, et al Abnormalities in normal appearing tissues in early primary progressive multiple sclerosis and their relation to disability: a tissue specific magnetisation transfer study. J Neurol Neurosurg Psychiatry 2006;77:40-5.

[53] Vrenken H, Geurts JJ, Knol DL, van Dijk LN, Dattola V, Jasperse B, et al. Wholebrain T1 mapping in multiple sclerosis: global changes of normal-appearing gray and white matter. Radiology 2006;240:811-20.

[54] Manfredonia F, Ciccarelli O, Khaleeli Z, Tozer DJ, Sastre-Garriga J, Miller DH, et al Normal-appearing brain $\mathrm{t} 1$ relaxation time predicts disability in early primary progressive multiple sclerosis. Arch Neurol 2007;64:411-5.

[55] Rovaris M, Gallo A, Valsasina P, Benedetti B, Caputo D, Ghezzi A, et al. Short-term accrual of gray matter pathology in patients with progressive multiple sclerosis: an in vivo study using diffusion tensor MRI. Neuroimage 2005;24:1139-46.

[56] Vrenken H, Pouwels PJ, Geurts JJ, Knol DL, Polman CH, Barkhof F, et al. Altered diffusion tensor in multiple sclerosis normal-appearing brain tissue: cortical diffusion changes seem related to clinical deterioration. J Magn Reson Imaging 2006;23:628-36.

[57] Chard DT, Griffin CM, McLean MA, Kapeller P, Kapoor R, Thompson AJ, et al Brain metabolite changes in cortical grey and normal-appearing white matter in clinically early relapsing-remitting multiple sclerosis. Brain 2002:125:2342-52.

[58] Geurts JJ, Reuling IE, Vrenken H, Uitdehaag BM, Polman CH, Castelijns JA, et al. MR spectroscopic evidence for thalamic and hippocampal, but not cortical, damage in multiple sclerosis. Magn Reson Med 2006:55:478-83.

[59] Benedict RH, Zivadinov R, Carone DA, Weinstock-Guttman B, Gaines J, Maggiore $C$, et al. Regional lobar atrophy predicts memory impairment in multiple sclerosis. AJNR Am J Neuroradiol 2005;26:1824-31.

[60] Prinster A, Quarantelli M, Orefice G, Lanzillo R, Brunetti A, Mollica C, et al. Grey matter loss in relapsing-remitting multiple sclerosis: a voxel-based morphometry study. Neuroimage 2006;29:859-67.

[61] Tekok-Kilic A, Benedict RH, Weinstock-Guttman B, Dwyer MG, Carone D, Srinivasaraghavan B, et al. Independent contributions of cortical gray matte atrophy and ventricle enlargement for predicting neuropsychological impairment in multiple sclerosis. Neuroimage 2007;36:1294-300.

[62] Lee M, Reddy H, Johansen-Berg H, Pendlebury S, Jenkinson M, Smith S, et al. The motor cortex shows adaptive functional changes to brain injury from multiple sclerosis. Ann Neurol 2000;47:606-13.

[63] Reddy H, Narayanan S, Arnoutelis R, Jenkinson M, Antel J, Matthews PM, et al. Evidence for adaptive functional changes in the cerebral cortex with axonal injury from multiple sclerosis. Brain 2000;123(Pt 11):2314-20.

[64] Filippi M, Rocca MA, Falini A, Caputo D, Ghezzi A, Colombo B, et al. Correlations between structural CNS damage and functional MRI changes in primary progressive MS. Neuroimage 2002;15:537-46.

[65] Rocca MA, Pagani E, Ghezzi A, Falini A, Zaffaroni M, Colombo B, et al. Functional cortical changes in patients with multiple sclerosis and nonspecific findings on conventional magnetic resonance imaging scans of the brain. Neuroimage 2003;19:826-36.

[66] Parry AM, Scott RB, Palace J, Smith S, Matthews PM. Potentially adaptive functional changes in cognitive processing for patients with multiple sclerosis and their acute modulation by rivastigmine. Brain 2003;126:2750-60.

[67] Cader S, Cifelli A, Abu-Omar Y, Palace J, Matthews PM. Reduced brain functional reserve and altered functional connectivity in patients with multiple sclerosis. Brain 2006;129:527-37.
[68] Audoin B, Ibarrola D, Ranjeva JP, Confort-Gouny S, Malikova I, Ali-Cherif A, et al. Compensatory cortical activation observed by fMRI during a cognitive task at the earliest stage of MS. Hum Brain Mapp 2003;20:51-8

[69] Agosta F, Valsasina P, Caputo D, Stroman PW, Filippi M. Tactile-associated recruitment of the cervical cord is altered in patients with multiple sclerosis. Neuroimage 2008;39:1542-8.

[70] Agosta F, Valsasina P, Rocca MA, Caputo D, Sala S, Judica E, et al. Evidence for enhanced functional activity of cervical cord in relapsing multiple sclerosis. Magn Reson Med 2008;59:1035-42.

[71] Gilmore C, Geurts J, Evangelou N, Bot J, van Schijndel R, Pouwels P, et al. Spinal cord grey matter lesions in multiple sclerosis detected by post-mortem high field MR imaging. Mult Scler 2008;15:180-8.

[72] Tsunoda I, Fujinami RS. Inside-out versus outside-in models for virus induced demyelination: axonal damage triggering demyelination. Springer Semin Immunopathol 2002;24:105-25.

[73] Stohlman SA, Hinton DR. Viral induced demyelination. Brain Pathol 2001;11:92-106.

[74] Zaadstra BM, Chorus AM, van BS, Kalsbeek H, van Noort JM. Selective association of multiple sclerosis with infectious mononucleosis. Mult Scler 2008;14:307-13.

[75] Pender MP, Greer JM. Immunology of multiple sclerosis. Curr Allergy Asthma Rep 2007;7:285-92.

[76] Serafini B, Rosicarelli B, Franciotta D, Magliozzi R, Reynolds R, Cinque P, et al. Dysregulated Epstein-Barr virus infection in the multiple sclerosis brain. J Exp Med 2007:204:2899-912.

[77] Zivadinov R, Zorzon M,Weinstock-Guttman B, Serafini M, Bosco A, Bratina A, et al. Epstein-Barr virus is associated with gray matter atrophy in multiple sclerosis. J Neurol Neurosurg Psychiatry 2009. (Electronic publication ahead of print).

[78] Huizinga R, Heijmans N, Schubert P, Gschmeissner S, 't Hart BA, Herrmann H, et al. Immunization with neurofilament light protein induces spastic paresis and axonal degeneration in Biozzi ABH mice. J Neuropathol Exp Neurol 2007;66: 295-304.

[79] Huizinga R, Gerritsen W, Heijmans N, Amor S. Axonal loss and gray matter pathology as a direct result of autoimmunity to neurofilaments. Neurobiol Dis 2008;32:461-70.

[80] Sun D, Whitaker JN, Huang Z, Liu D, Coleclough C, Wekerle H, et al. Myelin antigen-specific CD8 + T cells are encephalitogenic and produce severe disease in C57BL/ 6 mice. J Immunol 2001;166:7579-87.

[81] Morris-Downes MM, Smith PA, Rundle JL, Piddlesden SJ, Baker D, Pham-Dinh D, et al. Pathological and regulatory effects of anti-myelin antibodies in experimental allergic encephalomyelitis in mice. J Neuroimmunol 2002;125:114-24.

[82] Smith PA, Heijmans N, Ouwerling B, Breij EC, Evans N, van Noort JM, et al. Native myelin oligodendrocyte glycoprotein promotes severe chronic neurological disease and demyelination in Biozzi ABH mice. Eur J Immunol 2005;35:1311-9.

[83] Amor S, Giovannoni G. Antibodies to myelin oligodendrocyte glycoprotein as a biomarker in multiple sclerosis-are we there yet? Mult Scler 2007;13:1083-5.

[84] Storch MK, Bauer J, Linington C, Olsson T, Weissert R, Lassmann H. Cortical demyelination can be modeled in specific rat models of autoimmune encephalomyelitis and is major histocompatability complex (MHC) haplotype-related. J Neuropathol Exp Neurol 2006;65:1137-42

[85] Gonsette RE. Oxidative stress and excitotoxicity: a therapeutic issue in multiple sclerosis? Mult Scler 2008;14:22-34.

[86] Bo L, Dawson TM, Wesselingh S, Mork S, Choi S, Kong PA, et al. Induction of nitric oxide synthase in demyelinating regions of multiple sclerosis brains. Ann Neurol 1994;36:778-86

[87] Mahad D, Ziabreva I, Lassmann H, Turnbull D. Mitochondrial defects in acute multiple sclerosis lesions. Brain 2008;131:1722-35.

[88] Lassmann H. Hypoxia-like tissue injury as a component of multiple sclerosis lesions. J Neurol Sci 2003;206:187-91.

[89] Breij EC, Brink BP, Veerhuis R, van den BC, Vloet R, Yan R, et al. Homogeneity of active demyelinating lesions in established multiple sclerosis. Ann Neurol 2008;63:16-25.

[90] Nave KA, Trapp BD. Axon-glial signaling and the glial support of axon function. Annu Rev Neurosci 2008;31:535-61.

[91] Rosenbluth J. Central myelin in the mouse mutant shiverer. J Comp Neurol 1980;194:639-48.

[92] Inoue Y, Nakamura R, Mikoshiba K, Tsukada Y. Fine structure of the central myelin sheath in the myelin deficient mutant shiverer mouse, with special reference to the pattern of myelin formation by oligodendroglia. Brain Res 1981;219:85-94.

[93] Griffiths I, Klugmann M, Anderson T, Yool D, Thomson C, Schwab MH, et al. Axonal swellings and degeneration in mice lacking the major proteolipid of myelin. Science $1998 \cdot 280: 1610-3$.

[94] Craner MJ, Newcombe J, Black JA, Hartle C, Cuzner ML, Waxman SG. Molecular changes in neurons in multiple sclerosis: altered axonal expression of Nav1.2 and Nav1.6 sodium channels and $\mathrm{Na}^{+} / \mathrm{Ca}^{2+}$ exchanger. Proc Natl Acad Sci U S A 2004:101:8168-73.

[95] Zivadinov R, Uxa L, Bratina A, Bosco A, Srinivasaraghavan B, Minagar A, et al. HLADRB1*1501, -DQB $1 * 0301$, -DQB1*0302, -DQB $1 * 0602$, and -DQB1*0603 alleles are associated with more severe disease outcome on MRI in patients with multiple sclerosis. Int Rev Neurobiol 2007;79:521-35.

[96] Dutta R, McDonough J, Yin X, Peterson J, Chang A, Torres T, et al. Mitochondrial dysfunction as a cause of axonal degeneration in multiple sclerosis patients. Ann Neurol 2006;59:478-89.

[97] Carelli V, Bellan M. Myelin, mitochondria, and autoimmunity: what's the connection? Neurology 2008;70:1075-6.

[98] Stys PK. Axonal degeneration in multiple sclerosis: is it time for neuroprotective strategies? Ann Neurol 2004;55:601-3. 
[99] Pitt D, Werner P, Raine CS. Glutamate excitotoxicity in a model of multiple sclerosis. Nat Med 2000;6:67-70.

[100] Newcombe J, Uddin A, Dove R, Patel B, Turski L, Nishizawa Y, et al. Glutamate receptor expression in multiple sclerosis lesions. Brain Pathol 2008;18:52-61.

[101] Geurts JJ, Wolswijk G, Bo L, Redeker S, Ramkema M, Troost D, et al. Expression patterns of Group III metabotropic glutamate receptors mGluR4 and mGluR8 in multiple sclerosis lesions. J Neuroimmunol 2005;158:182-90.

[102] Geurts JJ, Wolswijk G, Bo L, van der Valk P, Polman CH, Troost D, et al. Altered expression patterns of group I and II metabotropic glutamate receptors in multiple sclerosis. Brain 2003;126:1755-66.

[103] Stover JF, Pleines UE, Morganti-Kossmann MC, Kossmann T, Lowitzsch K, Kempski OS. Neurotransmitters in cerebrospinal fluid reflect pathological activity. Eur J Clin Invest 1997;27:1038-43.

[104] Srinivasan R, Sailasuta N, Hurd R, Nelson S, Pelletier D. Evidence of elevated glutamate in multiple sclerosis using magnetic resonance spectroscopy at $3 \mathrm{~T}$. Brain 2005;128:1016-25.

[105] Werner P, Pitt D, Raine CS. Multiple sclerosis: altered glutamate homeostasis in lesions correlates with oligodendrocyte and axonal damage. Ann Neurol 2001;50:169-80.

[106] Ouardouz M, Coderre E, Zamponi GW, Hameed S, Yin X, Trapp BD, et al. Glutamate receptors on myelinated spinal cord axons: II) AMPA and GluR5 receptors. Ann Neurol 2009;65:160-6.

[107] Matute C, Alberdi E, Domercq M, Sanchez-Gomez MV, Perez-Samartin A, Rodriguez-Antiguedad A, et al. Excitotoxic damage to white matter. J Anat 2007;210:693-702.

[108] Tekkok SB, Ye Z, Ransom BR. Excitotoxic mechanisms of ischemic injury in myelinated white matter. J Cereb Blood Flow Metab 2007;27:1540-52.
[109] Ouardouz M, Nikolaeva MA, Coderre E, Zamponi GW, McRory JE, Trapp BD, et al. Depolarization-induced $\mathrm{Ca}^{2+}$ release in ischemic spinal cord white matter involves L-type $\mathrm{Ca}^{2+}$ channel activation of ryanodine receptors. Neuron 2003;40: 53-63.

[110] Young EA, Fowler CD, Kidd GJ, Chang A, Rudick R, Fisher E, et al. Imaging correlates of decreased axonal $\mathrm{Na}^{+} / \mathrm{K}^{+}$ATPase in chronic multiple sclerosis lesions. Ann Neurol 2008;63:428-35.

[111] Trapp B, Stys PK. Virtual hypoxia and chronic necrosis of demyelinated axons in multiple sclerosis. Lancet Neurol in press.

[112] Zivadinov R, Reder AT, Filippi M, Minagar A, Stuve O, Lassmann H, et al. Mechanisms of action of disease-modifying agents and brain volume changes in multiple sclerosis. Neurology 2008;71:136-44.

[113] Evangelou N, Esiri MM, Smith S, Palace J, Matthews PM. Quantitative pathological evidence for axonal loss in normal appearing white matter in multiple sclerosis. Ann Neurol 2000;47:391-5.

[114] Chen JT, Collins DL, Atkins HL, Freedman MS, Galal A, Arnold DL. Brain atrophy after immunoablation and stem cell transplantation in multiple sclerosis. Neurology 2006;66:1935-7.

[115] Kelemen A, Dwyer MG, Horakova D, Vaneckova M, Havrdova E, Zivadinov R Measurement of gray matter volume is less susceptible to pseudoatrophy effect than that of white matter or whole brain volume in patients with multiple sclerosis. Results from Avonex-Steroids-Azathioprine combination study. Mult Scler 2008;14:280:S11.

[116] Zivadinov R, Locatelli L, Cookfair D, Srinivasaraghavan B, Bertolotto A, Ukmar M, et al. Interferon beta-1a slows progression of brain atrophy in relapsing-remitting multiple sclerosis predominantly by reducing gray matter atrophy. Mult Scler 2007;13:490-501. 